\title{
Effect of Hibernation on Sodium and Chloride Ion Transport in Isolated Frog Skin
}

\author{
Danuta Izabela KOSIK-BOGACKA and Tomasz TYRAKOWSKI
}

Accepted September 20, 2006

\begin{abstract}
KOSIK-BOGACKA D. I., TYRAKOWSKI T. 2007. Effect of hibernation on sodium and chloride ion transport in isolated frog skin. Folia biol. (Kraków) 55: 47-51.

The aim of the study was to evaluate the effect of hibernation on electrophysiological parameters of isolated frog skin under control incubation (Ringer solution) and after inhibition of $\mathrm{Na}^{+}$and $\mathrm{Cl}^{-}$transepithelial transport by application of amiloride and bumetanide. The transepithelial electrical potential difference (PD in $\mathrm{mV}$ ) was measured before and after mechanical stimulation of isolated frog skin. The tissues were mounted in a modified Ussing chamber. The results revealed a reduced PD of frog skin during hibernation. In February, as compared with November, PD of frog skin incubated in Ringer solution decreased by about $50 \%$. Hibernation also affected hyperpolarization (dPD) of frog skin after mechanical stimulation. In November and December, dPD was about $50 \%$ and $30 \%$ lower, respectively, compared with the subsequent two months of the experiment. The incubation of frog skin with amiloride, a sodium ion channel blocker, resulted in reduced values of all measured electrophysiological parameters irrespective of the phase of hibernation. After application of chloride ion transport inhibitor (bumetanide), the PD in November and December decreased compared with the control incubation by about $80 \%$ and $75 \%$, while in January and February by about $40 \%$ and $25 \%$, respectively. In January and February dPD increased by four times and three times as compared with November and December. Hibernation reduces net ion flow in isolated frog skin. During the initial period of hibernation the sensitivity of the skin to mechanical stimulation also decreases. Towards the end of hibernation, on the other hand, excitation of mechanosensitive ion channels takes place.
\end{abstract}

Key words: Hibernation, ion transport, isolated frog skin, Rana esculenta.

Danuta I. KOSIK-BOGACKA, Chair and Department of Biology and Medical Parasitology, Pomeranian Medical University, Powstańców Wielkopolskich 72, 70-111 Szczecin, Poland. E-mail:kodan@sci.pam.szczecin.pl

Tomasz TYRAKOWSKI, Department of Pathobiochemistry and Clinical Chemistry Medical University in Bydgoszcz, M. Skłodowskiej-Curie 9, 85-094 Bydgoszcz, Poland.

E-mail: tomtyr@aci.amb.bydgoszcz.pl

Abbreviations:

AMI - amiloride

BUME - bumetanide

dPD - difference between maximum stimulation value of transepithelial electrical potential difference and the one immediately before the stimulation procedure (in $\mathrm{mV}$ )

PD - transepithelial electrical potential difference (in $\mathrm{mV}$ )

\section{$\mathrm{RH}$ - Ringer solution}

Two characteristic phases can be distinguished in the annual life cycle of amphibians inhabiting the temperate zone, i.e. a period of activity and a period of hibernation, during which amphibians do not feed and show little activity (DZIUBEK 1987). In hibernating frogs, hydration of the system in- creases (ZAMACHOWSKI 1968) and active transport in the mesonephros changes (DE PISCEIS POLVER et al. 1988; FENOGLIO et al. 1996). Reduced temperature of the habitat during winter also affects physiological processes that take place in the skin of frogs, including respiration and transport of water and ions (FOX 1984; MULLER 1979). DE PICEIS POLVER et al. (1988) observed that lowering the temperature of incubation solution to $4^{\circ} \mathrm{C}$ resulted in a reduced electrical potential difference of frog skin by about $55 \%$, as compared with incubation at $20^{\circ} \mathrm{C}$. There is, however, no data on ion transport in frog skin in each month of hibernation. Hence, the aim of this study was to evaluate the effect of hibernation on the electrophysiological parameters of frog skin under controled conditions as well as after pharmacological modification with amiloride and bumetanide. 


\section{Material and Methods}

The study was performed on adult specimes of Rana esulenta L. of both sexes. Frogs were collected in October and kept at $1.5-2^{\circ} \mathrm{C}$ in constant darkness.

The experiment had been previously approved by the local Universities Committee for Ethical Animal Experiments.

Experiments consisted of measurements of transepithelial electrical potential difference (PD) of the skin placed in an Ussing apparatus (KOEFOED-JOHNSEN \& USSING 1958). The Ussing chamber had been modified as described previously (KOSIK-BOGACKA \& TYRAKOWSKI 2002, 2003; TYRAKOWSKI et. al. $1998 \mathrm{a}, \mathrm{b})$. The measuring equipment consisted of a voltage/current clamp apparatus - EVC 4000 (WPI, USA) and a recorder - BD 111 (Kipp and Zonnen, Netherlands), which were connected to the Ussing apparatus by means of $\mathrm{Ag} / \mathrm{AgCl}$ electrodes and agar bridges.

The frogs were stunned, decapitated and doubly pithed. Abdominal skin was carefully excised, divided into fragments about $2 \mathrm{~cm}^{2}$, and incubated in a well-aerated solution before mounting in the Ussing apparatus.

Mechanical stimulation was performed by directing a jet of bathing medium on the mucosal surface of the skin. The standard stimulation consisted of 8-9 jets of fluids, with a total volume of $2.45 \mathrm{ml}$ applied over $30 \mathrm{~s}$. The dPD which denotes the hyperpolarization after mechanical stimulation was calculated as the difference between maximum stimulation and the control value.
The solutions used throughout the experiment were as follows - (concentrations in $\mathrm{mM}$ ):

- Ringer solution $\left(\mathrm{Na}^{+}\right.$147.2, $\mathrm{K}^{+} 4.0, \mathrm{Ca}^{+2} 4.4$, $\mathrm{Cl}^{-}$155.6, HEPES -N-2-hydroxyethyl-piperazine-N,-2-ethanesulfonic acid 10.0) - control group,

- Ringer solution with amiloride (0.1) model of inhibited absorption of $\mathrm{Na}^{+}$ions,

- Ringer solution with bumetanide (0.1) model of inhibited absorption of $\mathrm{Cl}^{-}$ions, (all supplied by Sigma-Aldrich Ltd., Poland).

Results are given as a mean standard error of the mean. Statistical evaluation was made by the Student's $t$-test in the "Statgraphics" computer program. Differences were statistically significant at the level of 0.05 .

\section{Results}

In the first month of the study, transepithelial electrical potential difference in isolated skin under control conditions was $-22.9 \pm 2.6 \mathrm{mV}$, while hyperpolarization after mechanical stimulation (dPD) was $-0.6 \pm 0.3 \mathrm{mV}$ (Table 1, Fig. 1a). PD oscillations during mechanical stimulation were caused by the jet flux of stimulating fluid from nozzle washing the mucosal surface of the tissue (Fig. 1a).

In December, the PD of frog skin decreased by about $30 \%$, whereas dPD increased by about $30 \%$ compared with its value recorded in November (Fig. 1b). In the subsequent month of the experiment, PD of the skin decreased by about $40 \%$,

Table 1

Effect of hibernation on electrophysiological parameters of isolated frog skin incubated in various experimental conditions

\begin{tabular}{|c|c|c|c|c|c|c|}
\hline \multirow{2}{*}{ Month } & \multicolumn{2}{|c|}{$\mathrm{RH}(\mathrm{n}=5)$} & \multicolumn{2}{|c|}{ AMI $(n=16)$} & \multicolumn{2}{|c|}{ BUME $(n=17)$} \\
\hline & $\begin{array}{l}\mathrm{PD} \\
\mathrm{mV}\end{array}$ & $\begin{array}{l}\mathrm{dPD} \\
\mathrm{mV}\end{array}$ & $\begin{array}{l}\text { PD } \\
\mathrm{mV}\end{array}$ & $\begin{array}{l}\mathrm{dPD} \\
\mathrm{mV}\end{array}$ & $\begin{array}{l}\mathrm{PD} \\
\mathrm{mV}\end{array}$ & $\begin{array}{l}\mathrm{dPD} \\
\mathrm{mV}\end{array}$ \\
\hline $\mathrm{XI}$ & $-22.9 \pm 2.6 \mathrm{a}$ & $-0.6 \pm 0.3 \mathrm{~b}$ & $-2.7 \pm 0.3 \mathrm{a}^{*}, \mathrm{c}$ & $-0.1 \pm 0.1 b^{*}$ & $-4.8 \pm 0.1 \mathrm{a}^{*}, \mathrm{~d}$ & $-0.8 \pm 0.0 \mathrm{e}$ \\
\hline XII & $-15.7 \pm 2.2 \mathrm{a}^{*}$ & $-0.8 \pm 0.2$ & $-2.0 \pm 0.3 a^{*}$ & $-0.0 \pm 0.0 \mathrm{~b}^{*}$ & $-4.0 \pm 0.8 \mathrm{a}^{*}$ & $-0.5 \pm 0.1 \mathrm{e}^{*}$ \\
\hline I & $-13.5 \pm 2.5 \mathrm{a}^{*}$ & $-1.2 \pm 0.3 b^{*}$ & $-3.7 \pm 0.6 \mathrm{a}^{*}, \mathrm{c}^{*}$ & $-0.1 \pm 0.1 b^{*}$ & $-8.7 \pm 2.7 \mathrm{a}^{*}, \mathrm{~d}^{*}$ & $-2.0 \pm 0.4 \mathrm{e}^{*}$ \\
\hline II & $-10.9 \pm 1.9 \mathrm{a}^{*}$ & $-1.2 \pm 0.3 b^{*}$ & $-2.0 \pm 0.2 \mathrm{a}^{*}$ & $-0.1 \pm 0.0 \mathrm{~b}^{*}$ & $-8.2 \pm 1.2 \mathrm{a}^{*}, \mathrm{~d}^{*}$ & $-1.5 \pm 0.3 \mathrm{e}^{*}$ \\
\hline
\end{tabular}

The values represent the means $\pm \mathrm{SEM}$. The $\mathrm{dPD}$ (in $\mathrm{mV}$ ) is the difference between maximum stimulation value of transepithelial electrical potential difference and the one immediately before stimulation procedure. The isolated skin was studied in Ussing chamber and the solutions applied throughout the experiments were:

$\mathrm{RH}$ - incubation, bathing and stimulation solutions were Ringer solution,

AMI - incubation, bathing and stimulation solutions were Ringer solution with amiloride,

BUME - incubation, bathing and stimulation solutions were Ringer solution with bumetanide;

$\mathrm{n}$ - number of experiments in parentheses;

*a, ${ }^{*} \mathrm{~b},{ }^{*} \mathrm{c},{ }^{*} \mathrm{~d}, \mathrm{e}^{*}$ - significantly different from the a, b, c, d, e at $\mathrm{P}<0.05$. 
while hyperpolarization after mechanical stimulation was twofold higher than in November (Fig. 1c). In February, PD diminished by about $20 \%$, whilst $\mathrm{dPD}$ remained unchanged and was the same as in January (Fig. 1d).

The addition of amiloride to the incubation medium caused a reduction of PD by about $90 \%$ in November, as compared with incubation in $\mathrm{RH}$ in

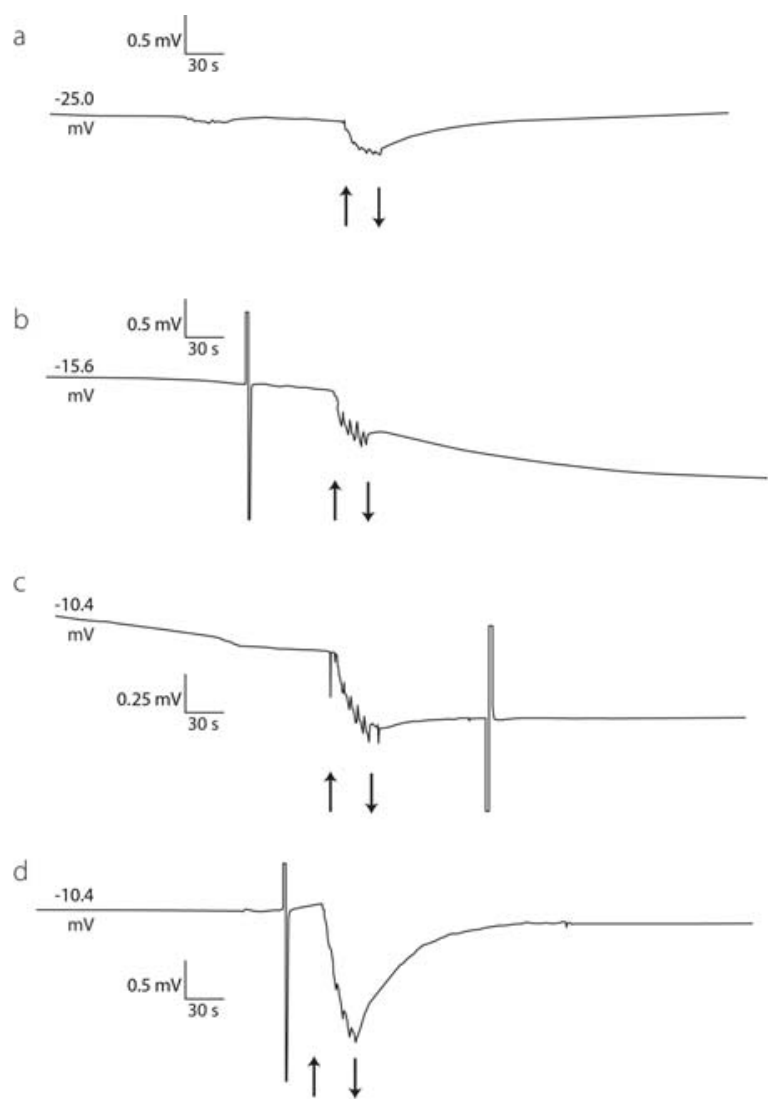

Fig. 1. The effect of mechanical stimulation on hyperpolarization of PD of isolated frog skin under control conditions in subsequent months of hibernation: November (a), December (b), January (c), and February (d). Tissues incubated and stimulated with Ringer solution. The arrows denote the beginning and end of the stimulation. A single experiment is shown.

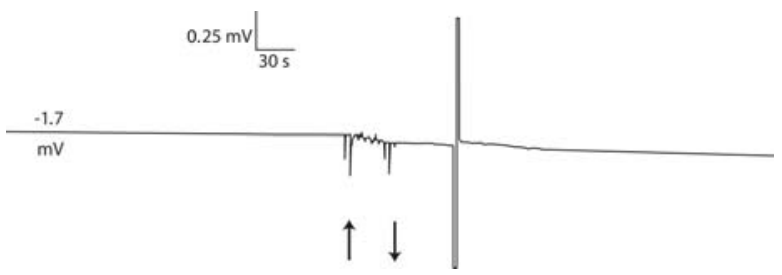

Fig. 2. The effect of amiloride on hyperpolarization after mechanical stimulation of isolated skin of hibernating frogs. Tissue incubated and stimulated with amiloride. The arrows denote the beginning and end of the stimulation. A single experiment is shown. the same month (Table 1). Mechanical stimulation did not elicit changes in transepithelial electrical potential difference, this also pertained to the subsequent month of observations (Fig. 2). In December PD of isolated skin decreased by about $30 \%$, whereas in January it increased by about $40 \%$ compared with November. In the last month of the experiment PD of the isolated frog skin decreased again and was comparable with the level recorded in December.

After addition of bumetanide to the incubation medium, a drop of PD by about $80 \%$ was recorded in November, whereas dPD increased by some $30 \%$ compared with its value after incubation under control conditions (Table 1, Fig. 3a). In December PD decreased by about $20 \%$, whereas hyperpolarization after mechanical stimulation decreased by $40 \%$, as compared with parameters recorded in November under the same treatment conditions (Fig. 3b). In the subsequent month of the study the parameters of isolated frog skin increased, PD increased by twofold and dPD fourfold (Fig. 3c) compared with November. In February PD of isolated frog skin decreased by about $10 \%$, while dPD diminished by about $25 \%$, as compared with the values in January (Fig. 3d).

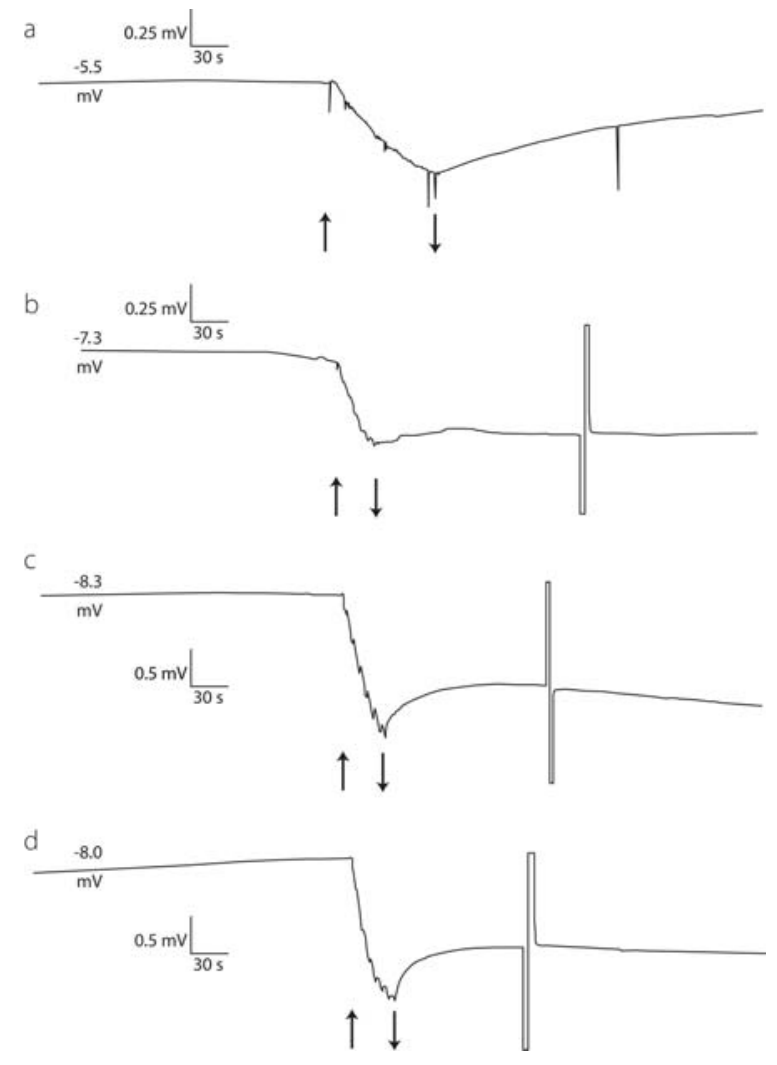

Fig. 3. The effect of bumetanide on hyperpolarization after mechanical stimulation of isolated frog skin in subsequent months of hibernation: November (a), December (b), January (c), and February (d). Tissues incubated and stimulated with bumetanide. The arrows denote the beginning and end of the stimulation. A single experiment is shown. 


\section{Discussion}

The skin, mesonephros, and urinary bladder of amphibians take part in ion exchange and the maintenance of water and mineral balance under varying conditions, including seasonal activity changes (FENOGLIO et al. 1996). Ion exchange in epithelial cells is possible due to ion channels and pumps localized in cellular membranes. Two transepithelial transport systems participate in generating the transepithelial electrical potential difference of frog skin, i.e. the secretory pathway for $\mathrm{Cl}^{-}$and the reabsorptive pathway for $\mathrm{Na}^{+}$ (KATZ \& NAGEL 1994). This leads to segregation of positive and negative ions by the frog skin epithelium (KOSIK-BOGACKA \& TYRAKOWSKI 2002, 2003). A classic system for in vitro transepithelial electrical potential difference measurements involves the Ussing chamber (KOEFOED-JOHNSEN \& USSING 1958).

The results of the presented experiment suggest that the transepithelial electrical potential difference of isolated frog skin after incubation under control conditions decreased with subsequent months of hibernation. In February, as compared with November, PD diminished by about $50 \%$ (Table 1). The decrease in this parameter was probably linked with ion channel blocking undergoing through subsequent months of hibernation. The process of hibernation also affected the sensitivity of frog skin to mechanical stimulation. In January and February the level of hyperpolarization after mechanical stimulation was twofold higher compared with the two remaining months of observations (Fig. 1). An increase of this parameter in the second phase of hibernation could have resulted from activation of a regulatory system preparing the frogs for the post-hibernation period, including the reproductive season.

In order to identify the transport pathway(s) of ions responsible for changes in the transepithelial electrical potential difference during hibernation of frogs, two ion transport inhibitors were applied, i.e. amiloride and bumetanide.

Amiloride, a recognised inhibitor of the apical epithelial sodium channel (AVENET 1992; KOSIKBOGACKA \& TYRAKOWSKI 2002, 2003; TYRAKOWSKI et al. 1998a) was applied for incubation. With amiloride present in the incubation and stimulating solutions, the value of the transepithelial electrical potential difference depends on chloride ion transport. Both literature data and the presented results demonstrate that the value of the transepithelial electrical potential difference of frog skin primarily depends on sodium ion transport (KATZ \& NAGEL 1994; KOSIK-BOGACKA \& TYRAKOWSKI $2002,2003)$. After incubation of the frog skin with amiloride, PD was lower compared with the control group (Table 1). The highest PD in this group was noted in January, which could have been caused by increased chloride ion transport. After incubation with amiloride, a lack of response to mechanical stimulation was also observed (Fig. 2).

Bumetanide, a well known inhibitor of $\mathrm{Na}(+) \mathrm{K}(+) 2 \mathrm{Cl}(-)$ cotransport (KOSIK-BOGACKA \& TYRAKOWSKI 2002, 2003; MOORE et al. 1995; STODDARD et al. 1985; TYRAKOWSKI et al. 1998b) was also applied. In the presence of bumetanide in incubation and stimulation solutions, the PD and $\mathrm{APD}$ depended entirely on sodium ion transport. After application of this inhibitor, the transepithelial electrical potential difference in November and December decreased compared with control incubation by about $80 \%$ and $75 \%$, while in January and February by about $40 \%$ and $25 \%$ (Table 1 ). In the last two months of the study, hyperpolarization after mechanical stimulation also increased (Fig. 3). The dPD was similar to that in the control group. These results confirm the previous hypothesis that in January and February additional activation of ion transport takes place, especially for chlorine ions.

The results of this study demonstrate that the free ion flow in isolated frog skin is reduced during hibernation. Towards the end of hibernation, stimulation of mechanosensitive ion channels commences and results in enhanced hyperpolarization.

\section{References}

AVENET P. 1992. Role of amiloride-sensitive sodium channels in taste. Soc. Gen. Physiol. Ser. 47: 271-279.

DE PiCeis Polver P., Fenoglio C., Gerzeli G., RAPuZzi G., BARNI S. 1988. Potassium-dependent p-nitrophenyl phosphatase and adenylate cyclase activity in Rana esculenta skin during natural hibernation and aquatic life: A cytochemical study. Arch. Biol. 99: 183-195.

DZIUBEK K. 1987. Glutathione metabolism in seleted organ sof Rana temporaria L. in the annual cycle and under different stresses. Part III. In developing of oocytes. Acta Biol. Crac. Zool. 29: 69-75.

Fenoglio C., VACCARONe R., Chiari P., Gervaso M. V. 1996. An ultrastructural and cytochemical study of the mesonephros of Rana esculenta during activity and hibernation. Eur. J. Morphol. 34: 107-121.

FoX H. 1984. Amphibian Morphogenesis. Human press. Clifton. New Jersey.

KATZ U., NAGEL W. 1994. Biophysics of ion transport across amphibian skin. (In: Amphibian Biology, The Integument, vol. 1, Heatwole, H., Barthalmus G. T. eds. Surrey Beaty and Sons PTY Ltd., 1994, Chipping Norton, Australia): 98-119.

KOEFOED-JOHNSEN V., USSING H. H. 1958. The nature of the frog skin potential. Acta Physiol. Scand. 42: 298-308.

KOSIK-BOGACKA D. I., TYRAKOWSKI T. 2002. Transepithelial transport of sodium and chloride ions in isolated skin of the frog, Rana esculenta L. Folia biol. (Kraków) 50: 107-114.

KOSIK-BOGACKA D. I., TYRAKOWSKI T. 2003. Effect of capsaicin and dimethyl sulphoxide (DMSO) on ion transport in isolated skin of frog (Rana esculenta). Folia biol. (Kraków) 51: $117-123$.

Moore M. L., George J. N., TuRner R. J. 1995. Anion dependence of bumetanide binding and ion transport by the 
rabbit parotid $\mathrm{Na}(+)-\mathrm{K}(+)-2 \mathrm{Cl}$ - co-transporter: evidence for an intracellular anion modifier site. Biochem. J. 309: 637-642.

MULLER H. K. 1979. The frogs as an experimental animal. (In: Frog Neurobiolog R. R. Linas, H. Precht eds. SpringerVerlag, Berlin-Heidelberg-New York): 1024-1039.

StOdDARD J. S., JAKOBSSON E., HeLMAN S. J. 1985. Basolateral membrane chloride transport in isolated epithelia of frog skin. A. J. Physiol. 249: C318-C329.

TYRAKOWSKI T., BANACH B., MOŚCIBRODA A., BARTŁOMOWICZ M., WoJCIECHOWSKA M. 1998. Reappraisal of amiloride action on transepithelial electrical potential difference of isolated tracheal wall. Arch. Immunol. Therp. Exp. Warszawa 46: 45-50 a.

TYRAKOWSKI T., BANACH B., GRECZKO I., BARTŁOMOWICZM. WOJCIECHOWSKA M. 1998. Electrophysiological study of the interaction between epithelium and the airway fluid lining. Int. Rev. Allergol. Clin. Immunol. 4: 59-65 b.

ZAMACHOWSKI W. 1968. Changes in the water content in the organism of the common frog (Rana temporaria L.) and the water frog (Rana esculenta L.) in the annual cycle. Acta Biol. Crac. Zool. 20: 181-189. 